\title{
SYNTHESIS OF ACRYLIC ESTERS IN PTC: KINETICS AND ECOLOGICAL ASPECTS
}

\author{
G. Torosyan', Ghazi Aidan², N. Torosyan³ \\ ${ }^{1}$ State Engineering University of Armenia, department of chemical technology \& environmental engineering, \\ Yerevan, Armenia, email: gagiktorosyan@seua.am \\ ${ }^{2}$ National Academy of Science of Republic of Armenia Institute of Geological Researches, Yerevan, Armenia \\ ${ }^{3}$ CSTO Institute, Yerevan, Armenia
}

\begin{abstract}
Abstact: Phase-Transfer Catalysis (PTC) technology is used in commercial manufacture. PTC is used also in pollution treatment processes. In the paper the synthesis of esters of acrylic, metacrylic acids, which have wide industrial application for production of unique polymeric materials, by phase transfer catalysis method is demonstrated / PTC/. It is necessary to notice, that the synthesis of acrylic acids through PTC is more important because these compounds are more sensitive to acidic and basic conditions. PTC is characterized by a high degree of useful use of substances involved in reaction, smaller consumption of materials and power resources. The work is devoted to technological problems of the synthesis of ethers in the aspect of environment's protection. The offered method for acrylic ester synthesis, in comparison with the traditional methods, has more advantages including high speed of process, soft condition of reaction allowing reduction of energy expenses, the complete exception of application of hazardous and dangerous organic solvents, by virtue of its sharp reduction of air pollution and reduction of wastewater effluent.
\end{abstract}

Keywords: Phase transfer catalysis (PTC), acrylic acid, alkyl halogenide, acrylic ester, kinetic characteristic

\section{Introduction}

In chemical technology processes, as a rule, there are many manufacturing stages, which can be supplemented by various recycling operations.

Phase Transfer Catalysis / PTC/is widely applied in the industry of organic synthesis due its advantages [1-2]. From the standpoint of the process chemistry PTC has the advantages of being a proven technology involving simple and easily evaluated procedures with high yield ( often $>90 \%$ ) and increased reaction rates, sometimes leading to enhanced selectivity [2]. Since a major task faced by chemical industry is the development and realization of necessary measures for exception of harmful influence of the enterprises on the environment, adoption of technologies producing fewer wastes, PTC corresponds perfectly to these criteria due to the ability to use $\mathrm{NaOH}$ as a base instead of more expensive and hazardous organic bases, viability in the water and avoidance of run-away conditions. PTC technology is also used in pollution prevention, pollution treatment and the removal or destruction of impurities in waste and product streams [2].

In our group it has been shown an opportunity of synthesis of ethers and esters in PTC conditions [3-5]. These investigations have allowed to develop the synthesis of unsaturated ethers such as allyl furfuryl, propargyl furfuryl ethers) and esters; esters of acrylic and methacrylic acids, which have wide application in the industry for synthesis of unique polymeric materials [6]. Furfuryl ethers and esters were used also for intramolecular Diels-Alder reaction [4].

$$
\begin{aligned}
\mathrm{CH}_{2}= & \mathrm{CX}-\mathrm{COOH}+\mathrm{RHal} \longrightarrow \mathrm{CH}_{2}=\mathrm{CX}-\mathrm{COOR}+\mathrm{HHal} \\
& \mathrm{X}=\mathrm{H}, \mathrm{CH}_{3} \\
& \mathrm{R}=\text { alkyl, alkenyl, furfuryl, } \mathrm{Hal}=\mathrm{Cl}, \mathrm{Br}
\end{aligned}
$$

This reaction was carried out in aqueous phase, when acrylic acid is stable [7]. But, it's known that reaction systems which lack aqueous phase are very attractive to chemists. Therefore, we have tried to carry out reactions with a smaller amount of water $(10 \mathrm{~N})$, thus having solved also an ecological task. We hope that the proposed synthesis of acrylic esters will give the chance for a choice of optimum variants environmental friendly technology by comparison with existing processes.

\section{Experimental \\ Synthesis}

The synthesis of acrylic esters is carried out by interaction of acrylic acid with alkyl halides in the presence of the sodium hydroxide in water solution (or $\mathrm{KOH}$ ), the catalytic amounts of quaternary ammonium salts (catamin $\mathrm{AB}$ - the mixture of NN-dimethyl-N-benzyl-N-alkyl $\left(\mathrm{C}_{12}-\mathrm{C}_{18}\right)$ ammonium chlorides, industrial SAC), hydroquinone, at the temperature $55-75^{\circ} \mathrm{C}$ during $1-1,5$ hours. The molar ratio of acid : alkyl halide : sodium hydroxide : quaternary ammonium salts - is $1: 1,2: 1,0: 0,1$. The amount of hydroquinone is 0,5 gram for $0,5 \mathrm{~mol}$ of acid. The simplicity of performance and the higher yields (75-90\%) of target products can predetermine the application of the present method in industry. 


\section{Acrylic acid benzyl ester}

$3,6 \mathrm{~g}(0,05 \mathrm{~mol})$ of acrylic acid have been placed in a flask, followed by $5 \mathrm{ml} 10 \mathrm{~N}$ of a water solution of $\mathrm{NaOH}, 0,7 \mathrm{~g}$ $(0,001 \mathrm{mg})$ catamin- $\mathrm{AB}$ as $50 \%$ water solution and $0,05 \mathrm{~g}$ hydroquinone. At room temperature $\left(18^{\circ} \mathrm{C}\right) 7,6 \mathrm{~g}(0,06 \mathrm{~mol})$ benzyl chloride were added dropwise during $20 \mathrm{~min}$. The mix was heated up to $75^{\circ} \mathrm{C}$ and reacted for $40 \mathrm{~min}$. Then the mixture cooled and extracted three times by ether (totally $100 \mathrm{ml}$ ). Etherial extract was dried up on $\mathrm{Na}_{2} \mathrm{SO}_{4}$. The product was overtaken under vacuum after removal of the ether. It constitutes 7,3g of benzyl acrilate $\left(90 \%\right.$, b.p. $114-117^{\circ} \mathrm{C} /$ $7 \mathrm{~mm}, \mathrm{~N}^{20}{ }_{\mathrm{D}}=1,5243$ [7]). IR, $\sqrt{ }, \mathrm{sm}^{-1}: 700,750,1490,1590,1625,1725,3030,3060,3090$. NMR, 5,06s $\left(\mathrm{CH}_{2}\right), 5,50$ $6,37 \mathrm{~m}\left(\mathrm{CH}=\mathrm{CH}_{2}\right), 7,11 \mathrm{~m}\left(\mathrm{C}_{6} \mathrm{H}_{5}\right)$. The same processes we make for furfurylic ester of acrylic acid.

\section{Acrylic acid allyl ester}

Similarly to the above mentioned conditions from $3,6 \mathrm{~g}(0,05 \mathrm{~mol})$ acrylic acid, $5 \mathrm{ml} 10 \mathrm{~N}$ of a water solution of $\mathrm{NaOH}$, $0,7 \mathrm{~g}(0,001 \mathrm{~mol})$ catamin- $\mathrm{AB}$ as $50 \%$ water solution, $0,05 \mathrm{~g}$ hydroquinone and 7,26g $(0,06 \mathrm{~mol})$ allyl bromide, $5,11 \mathrm{~g}$ $(91 \%)$ allyl acrylate (b.p. $119-120^{\circ} \mathrm{C} / 680 \mathrm{~mm}, \mathrm{~N}^{20}{ }_{\mathrm{D}}=1,4335$ [7]) have been produced.

\section{Acrylic acid n-amyl ester}

Similarly to the above mentioned conditions from $3,6 \mathrm{~g}(0,05 \mathrm{~mol})$ acrylic acid, $5 \mathrm{ml} 10 \mathrm{~N}$ of a water solution of $\mathrm{NaOH}$, $0,7 \mathrm{~g}(0,001 \mathrm{~mol})$ catamin- $\mathrm{AB}$ as $50 \%$ water solution, $0,05 \mathrm{~g}$ hydroquinone and $9,1 \mathrm{~g}(0,06 \mathrm{~mol}) \mathrm{n}$ - amyl bromide, $5 \mathrm{~g}(70$ $\%$ ) n-amyl acrylate (b.p. $53-54{ }^{\circ} \mathrm{C} / 9 \mathrm{~mm}, \mathrm{~N}_{\mathrm{D}}^{20}=1,4240$ [7]) have been produced.

\section{Acrylic acid glycidyl ester}

Similarly to the above mentioned conditions from $3,6 \mathrm{~g}(0,05 \mathrm{~mol})$ acrylic acid, $5 \mathrm{ml} 10 \mathrm{~N}$ of a water solution of $\mathrm{NaOH}$, $0,7 \mathrm{~g}(0,001 \mathrm{~mol})$ catamin- $\mathrm{AB}$ as $50 \%$ water solution, $0,05 \mathrm{~g}$ hydroquinone and $5,55 \mathrm{~g}(0,06 \mathrm{~mol})$ epychlorhydrin, $4,38 \mathrm{~g}$ (70 \%) glycidyl acrylate (b.p. $162-163^{\circ} \mathrm{C} / 80 \mathrm{~mm}, \mathrm{~N}^{20}=1,4820$ ) have been produced. IR, $\sqrt{ }, \mathrm{sm}^{1}{ }^{1}, 1725$. NMR: 1,60$1,68 \mathrm{~m}\left(3 \mathrm{H}, \mathrm{CH}-\mathrm{CH}_{2}\right), 4,21 \mathrm{t}\left(2 \mathrm{H}, \mathrm{OCH}_{2}\right), 5,65-6,35 \mathrm{~m}\left(3 \mathrm{H}, \mathrm{CH}=\mathrm{CH}_{2}\right)$.

\section{Metacrylic acid n-butyl ester}

Similarly to the above mentioned conditions from $4,3 \mathrm{~g}(0,05 \mathrm{~mol})$ metacrylic acid, $5 \mathrm{ml} 10 \mathrm{~N}$ of a water solution of $\mathrm{NaOH}$, $0,7 \mathrm{~g}(0,001 \mathrm{~mol})$ catamin- $\mathrm{AB}$ as $50 \%$ water solution, $0,05 \mathrm{~g}$ hydroquinone and $8,22 \mathrm{~g}(0,06 \mathrm{~mol}) \mathrm{n}$-butyl bromide, $3,9 \mathrm{~g}$ $(55 \%)$ n-butyl metacrylate (b.p. $60-61{ }^{\circ} \mathrm{C} / 12 \mathrm{~mm}, \mathrm{~N}^{20}{ }_{\mathrm{D}}=1,4256$ [7]) have been produced.

\section{Kinetics}

We carried out also the definition of kinetic characteristics of the synthesis of a more interesting monomer - allyl acrylate. The reaction mixture was heated up to necessary temperature, which was kept constant during 1 hour. The analysis was done every 10 minutes. (Figure1). The reaction temperature was varied at the limits of $25-65^{\circ} \mathrm{C}$. Activation energy (E) and $\mathrm{K}_{\mathrm{o}}$ graphically determined from Arrhenius coordinates:

$$
\begin{aligned}
& \mathrm{E}=55625 \text { kjoule/kmol (13,28 kkal } / \mathrm{mol}) \\
& \mathrm{Ko}=1,922 \times 107 \text { m } \\
& 3,078 /(\text { kmoll, } 026 \text { min) }
\end{aligned}
$$

It had been established that the kinetic of reaction acrylic acids with allyl bromide in PTC conditions can be described by the equation:

$$
-\frac{d C_{a}}{d \tau}=k C_{a}{ }^{1975} C_{B}{ }^{0,051},
$$

Where: $K=1,922 \cdot 10^{7} e^{-\frac{55625}{8,314 \cdot T}}$

$\mathrm{C}_{\mathrm{A}}$ - concentration of acrylic acid

$\mathrm{C}_{\mathrm{B}}$ - concentration of allyl bromide

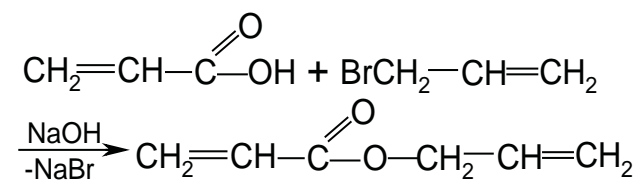




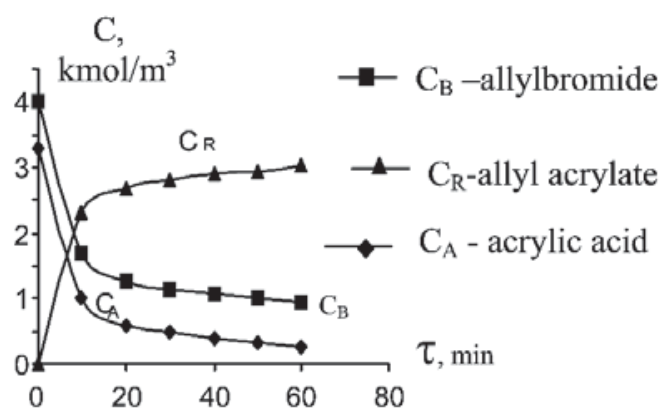

Fig. 1. The kinetic curves of the charge initial substances and accumulation of a product of reaction at the synthesis of allyl acrylate at $t=65^{\circ} \mathrm{C}$.

\section{Results and discussion}

The preparation of acrylic esters is an important synthetic reaction for which a variety of procedures have been developed during the last 50-60 years [7]. Traditionally the esters are produced by interaction of carbonic acids with alcohols in the presence of strong acids at higher temperatures $-105-121^{\circ} \mathrm{C}$ [7], argon current at $90^{\circ} \mathrm{C}$ [8], and the period of reaction was $55-60 \mathrm{~h}$ at $20-25^{\circ} \mathrm{C}$ [9]. The symmetric ether is formed also from the appropriate alcohol in acidic medium that creates difficulties for isolation of the desirable product [8]. It is necessary to note, that in case of the excess of alkali (the double excess of alkali is usual in alkylation reaction in PTC conditions) the yield of ester falls [3]. The reaction of hydrolysis of an ester takes place in any case.

In the reaction conditions another by-product, the derivative of propionic acid was formed [10]. Environmentally, the strong acidic conditions are less preferable than the basic ones [11]. Besides, as a rule, because of convertibility of the process in acidic medium, it is rather difficult to reach high yields of desirable product, which also requires additional expenses for neutralization of the reaction mixture by alkali materials [12]. Such technology differs by complexity and necessity of huge equipment which is difficult to operate. The ion exchange materials are expensive, quickly fail, require difficult regeneration, during which the huge amount of wastewater is formed [13]. Other method of this ester synthesis consists of interaction of alkyl halogen or other esters with the acrylic acid salts in the presence of organic solvents, acetonitrile, dimethylformamide and other expensive, hazardous and fire-explosive solvents. The toxicity of this solvents in atmosphere within the limits of $10 \mathrm{mg} / \mathrm{m}^{3}$, their accumulation in organism results in a acute poisonings which is observed initialy by narcotic action or excitation, frustration of coordination and spasm infringement of breath.

Obtained kinetic equation allows us to determine the optimum parameters of synthesis of acrylic esters in the simple hashing type reactor.

The greatest disadvantage of acrylic esters synthesis from salts is the formation of metal salts under anhydrous conditions [1,2]. Acrylic acid is converted into organic salts by the reaction with sodium or sodium hydride. The use of PTC to synthesize acrylic ethers improves the conventional methods since PTC has the advantage that the acrylic salt is synthesized in situ directly by the reaction of acid with alkaline solution in the aqueous solution. The final product is readily removed from the organic solvent simply by evaporation of solvent. The solvent in our case is not applied, as an organic phase enters itself. The quantity of used water is reduced also.

The reaction has appeared of the second order under the relation of acrylic acid, and zero - in relation to allyl bromide. Obtained equation allows calculating optimum parameters of process and reactor of ideal mixture for the synthesis of allyl acrylate.

The kinetics of the described synthesis of allyl acrylate testifies for the benefit of the PTC mechanism. Really, the order of reaction for allyl acrylate $\alpha_{B}=0,051$ (i.e. very close to zero) shows that the process is determined by the diffusion of acrylate ions from water phase into the organic one, which is consisted only from allyl bromide. The rather loe level of energy of activation also is determined by the contribution of the diffusion factor.

The synthesis of acrylic esters is carried out in a multi section apparatus, filled with strong acidic ion exchanger.

Obtained kinetic equation allows us to determine the optimum parameters of synthesis of acrylic esters in the simple hashing type reactor.

\section{Conclusion}

Procedures based on PTC in the substitutions usually excel over traditional methods owing to their simplicity, high yields and quality of final products. This method is especially valuable for reaction with compounds sensitive to water. 
The offered method for acrylic ester synthesis in comparison with the traditional methods has more advantages: high speed of process, soft condition of reaction allowing lowering of a power expenses, the complete exception of application of hazardous and dangerous organic solvents, by virtue of - it is sharp reduction of air pollution, much smaller volumes of wastewater. It should be note that the in offered synthesis of acrylates the alkylating agent - allyl bromide is used completely. All of this is devoted to technological problems of the synthesis of ethers in the aspect of protection of environment.

\section{Acknowledgement} Armenia.

These studies were supported by the Special State Scientific Program of State Engineering University of

\section{References}

[1]. Sharma, M. Application of phase transfer catalysis in the chemical industry. Handbook of PTC, Blackie Academic and Profesional, London, Wanheim, New York, Tokyo, Melburne. 1997, pp 168-199.

[2]. Babayan, A.; Torosyan, G., The Stage of PTC development. The Journal of Mendeleev Society, Revue. 1986, 12, 126-135.

[3]. Nazaretyan, A.; Torosyan, G.; Babayan, A. The Journal of Arm.Chim., 1984, 37, 15-17.

[4]. Torosyan, G. Journal of organic chemistry in Russian. 2002, 38, 1542-1543.

[5]. Torosyan, G.; Nazaretyan, A.; Khachatryan, M. Proceedings of Enginering Academy of Armenia, 2006, 3, 651653.

[6]. Marek, O.; Tomka, M. Acrylic polymers, M-L.in Russian. 1966, p 215.

[7]. Sovetskaja Enciklopedija, M. Polymer Encyclopedy in Russian. 1974, 1, p35.

[8]. Alchinger, H.; Fried, M.; Nestler, G. (1998), BASF AG, - No. 19648743.9, Russian Referative Zournal /RRZ/, (1999), 10H36P.

[9]. Pat.5491244 USA (1995) Acrylic acid ethers, RRZ (1996), 10 Í37 P.

[10]. Siga A. (1975), Acrylic esters, "Seni, Sen,” 27, No. 7, 292-306. RRZ (1976), 5H61.

[11]. Makosza, M; Fedorynski PTC catalyzed reactions under basic conditions. Handbook of PTC, Blackie Academic and Profesional, London, Wanheim, New York, Tokyo, Melbourne. 1975, pp135-168.

[12]. Pat. 5360926 USA Acrylate synthesis, RRZ in Russian, 1996, 11 Í32 P.

[13]. Osborn, G. Synthetic ion exchange materials, translates from English to Russian by M., Mir. 1986, p 321. 